\title{
Direito à moradia e o Programa Terra Legal na Amazônia: um estudo sob o enfoque da igualdade de capacidades de Amartya Sen
}

\section{Right to housing and the Terra Legal Program in the Amazon: a study under the equality of capabilities of Amartya Sen}

\author{
Gabriel Moraes Outeiro ${ }^{1}$ \\ Daniella Maria dos Santos Dias ${ }^{2}$
}

\begin{abstract}
Resumo
O direito à moradia se revela como uma necessidade primária do ser humano, reconhecida como um direito fundamental, inscrito no art. 6o da Constituição Federal. Trata-se de um direito que compreende diversas dimensões, como a segurança jurídica da posse do imóvel e a existência de um espaço que resguarde a intimidade e possibilite o repouso de seu titular. Acontece que, com a proliferação de assentamentos informais, a regularização fundiária urbana tem se mostrado como uma alternativa para a garantia daquele direito e da promoção da cidadania. Reconhecendo este quadro, o Governo Federal elaborou o Programa Terra Legal de regularização fundiária na Amazônia, posteriormente alterado pela Lei. 13.465/2017. Desta forma, esta pesquisa tem por objetivo geral analisar a estrutura jurídica deste Programa na modalidade urbana. Como referencial teórico adotou-se a concepção de igualdade de capacidades de A. Sen. Utilizou-se de uma abordagem de natureza teórica, apoiada em fontes secundárias, e, como procedimento metodológico, de pesquisa bibliográfica, documental e descritiva. Como principal resultado constatou-se que as alterações na estrutura jurídica do Programa Terra Legal, a despeito de terem facilitado a regularização fundiária urbana, podem levar à grilagem de terras e à exclusão socioespacial.
\end{abstract}

Palavras-chave: Direito à moradia; Igualdade de capacidades; Programa Terra Legal; Regularização fundiária urbana; Amazônia.

\section{Abstract}

The right to housing is revealed as a primary need of the human being, recognized as a fundamental right, inscribed in art. 6 of the Federal Constitution. It is a right that comprises several dimensions, such as the legal certainty of ownership of the property and the existence of a space that safeguards the privacy and allows the resting of its owner. As a result of the proliferation of informal settlements, urban land regularization has proven to be an alternative for the guarantee of that right and the promotion of citizenship. Recognizing this situation, the Federal Government prepared the Terra Legal Program for land regularization in the Amazon, later amended by Law $13,465 / 2017$. In this way, this research has as general objective to analyze the legal structure of this

\footnotetext{
${ }^{1}$ Doutor em Desenvolvimento Socioambiental pelo NAEA/UFPA. Doutorando em Direito pelo PPGD/UFPA. Mestre em Direito pelo PPGD/UFPA. Especialista em Direito Tributário pela Universidade AnhangueraUniderp. Diretor-Geral do Instituto de Ciências Sociais Aplicadas da Universidade Federal do Sul e Sudeste do Pará - ICSA/Unifesspa. Professor da Unifesspa. Advogado. Universidade Federal do Sul e Sudeste do Pará/Universidade Federal do Pará. Brasil. E-mail: gmouteiro@gmail.com

2 Doutora em Direito pela Universidade Federal de Pernambuco. Professora Titular da Universidade Federal do Pará (UFPA) e professora do Instituto de Ciências Jurídicas e do Programa de Pós-Graduação em Direito da UFPA; Especialista em Direito Ambiental e em Educação Ambiental pela UFPA; Especialista em Direito Agrário pelo CESUPA. Promotora de Justiça. Universidade Federal do Pará/Universidade Federal do Sul e Sudeste do Pará. Brasil. E-mail: diasdaniella@gmail.com
} 
Program in the urban modality. As a theoretical reference, the conception of equality of capacities of A. Sen was adopted. It was used a theoretical approach, supported by secondary sources, and as a methodological procedure of bibliographic, documentary and descriptive research. As a main result, changes in the legal structure of the Terra Legal Program, despite facilitating urban land regularization, may lead to land grabbing and socio-spatial exclusion.

Keywords: Right to housing; equality of capabilities; Terra Legal Program; Urban land regularization; Amazon.

\section{Introdução}

O Brasil tem experimentado uma expansão no número de habitações irregulares ao longo das últimas décadas em todo o país (IBGE, 2015), dentre as quais parte está em situação de inadequação fundiária urbana.

São consideradas irregulares as ocupações inseridas em locais que não atendem às normas de ocupação e parcelamento do solo, podendo ser imóveis localizados em favelas, em loteamentos e conjuntos habitacionais irregulares, em loteamentos clandestinos e em outras formas de assentamentos precários marcados por alguma forma de irregularidade administrativa e patrimonial, denominados de assentamentos informais (ROLNIK, 2006).

Em contraposição a esta realidade, a Constituição Federal (CF) de 1988 prevê um rol de direitos fundamentais, destinados a garantir a todos uma vida digna. Deste conjunto de direitos, um grupo em especial chama a atenção, por possuir certas peculiaridades. Os direitos sociais têm como finalidade assegurar a igualdade material entre os indivíduos, servindo como mecanismo de promoção de igualdade e de bem-estar (COURTIS; ABRAMOVICH, 2006).

Dentre estes direitos sociais, está o direito à moradia, que se revela como uma necessidade primária do ser humano, reconhecida como um direito fundamental, inscrito no art. 60 da Constituição Federal, por meio da Emenda Constitucional no 26 de 2000. A Lei Maior assegura o direito social à moradia quando estabelece, por meio da política urbana, a promoção da redução das desigualdades na ocupação do espaço urbano.

Diante deste quadro, um arcabouço normativo foi sendo elaborado com vistas à construção de espaços urbanos inclusivos, dando densidade ao comando constitucional. Acontece que ao se reconhecer a existência de assentamentos informais consolidados nas cidades brasileiras, a 
regularização fundiária urbana (Reurb) pode ser uma alternativa mais adequada de política pública do que a construção de parques habitacionais ou a remoção forçada de moradores de baixa renda.

Nesse sentido, a Reurb pode garantir a segurança jurídica da posse e o direito social à moradia, sendo um processo multidimensional, que combina a regularização jurídica com a urbanística (FERNANDES, 2006).

Com efeito, apesar de haver problemas quanto à regularidade de imóveis em todo o país, em 2008, o Governo Federal constatou que o quadro de indefinição fundiária atingia cerca de 50\% do território da Amazônia (BRITO; BARRETO, 2010), o que o levou a editar a Medida Provisória (MP) no 458/2009, posteriormente convertida na Lei no 11.952/2009, que instituiu o Programa Terra Legal (PTL) de regularização fundiária na Amazônia Legal.

Desta forma, esta pesquisa tem por objetivo geral analisar a estrutura jurídica do PTL de regularização fundiária na modalidade urbana.

Para alcançar seu objetivo, adotou-se como referencial teórico a concepção de igualdade de capacidades de A. Sen, que pode ser compreendida tanto como uma concepção de justiça distributiva (KYMLICKA, 2006), de igualdade distributiva restrita (VITA, 2008) ou de igualdade material (OUTEIRO; OLIVEIRA; NASCIMENTO, 2016).

Utilizou-se de uma abordagem de natureza teórica, apoiada em fontes secundárias, e, como procedimento metodológico, de pesquisa bibliográfica, documental e descritiva.

A exposição dos resultados da pesquisa foi organizada em três seções. Primeiramente, é apresentada a concepção de igualdade de capacidades de A. Sen e como seu pensamento pode ser utilizado para servir de baliza para analisar o direito à moradia. No capítulo seguinte o direito à moradia é examinado, à luz do referencial teórico, para na seção seguinte analisar o PTL. Por fim, são tecidas as conclusões da pesquisa.

\section{A Igualdade de Capacidades}

Ao iniciar a discussão sobre a abordagem de capacidades é importante compreenderr que Amartya Sen é um professor indiano de filosofia e economia, laureado com o prêmio Nobel de Ciências Econômicas, que se interessou por discussões sobre a pobreza e a igualdade a partir da convivência com a escassez de recursos por parte da população na Índia (SEN, 2000). 
Os seus estudos sobre bem-estar e pobreza contribuíram para a elaboração de outra forma de medir o desenvolvimento de um país ou região por meio do Índice de Desenvolvimento Humano (IDH), em detrimento do Produto Interno Bruto (PIB) ou de outras fórmulas que consideram apenas a riqueza produzida ou o crescimento econômico, ignorando fatores importantes, como qualidade de vida, educação e expectativa de vida.

Seu pensamento político está dentro do chamado liberalismo igualitário (GARGARELLA, 2008), no qual estão inseridos Jonh Rawls (2008), Ronald Dworkin (2005) e Kymlicka (1995), apesar da divergência entre as concepções de cada um.

Para Fleischcker (2006), a discussão sobre o que é justiça passa pela distribuição de riquezas entre os membros de uma sociedade e remonta à Antiguidade Clássica, com a obra Ética a Nicômaco de Aristóteles (2001). Atualmente a discussão envolve a distribuição de bens básicos, sendo necessário situar ou definir qual o papel do Estado e quais políticas públicas são necessárias, seja no campo da saúde, da previdência social e da educação, dentre outras áreas.

Assim, o que une estes autores envolve o reconhecimento de que o Estado deve proteger um conjunto básico de direitos, sendo responsável por garantir algum nível de bem-estar e que o Estado deve ser neutro na definição do que é uma vida boa (VITA, 2008).

Nesses termos, A. Sen $(2008 ; 2011)$ reconhece a influência da concepção de justiça de J. Rawls (2008), que em síntese, propõe uma concepção de igualdade, na qual princípios de justiça são escolhidos numa posição de prudência entre os membros de uma sociedade, sendo necessário equilibrar a adoção de liberdade econômica, responsabilidade individual e circunstâncias sociais e naturais que não foram escolhidas, para permitir a (re)distribuição de bens primários, como liberdades e renda.

Por outro lado, Dworkin (2005) defende a igualdade de recursos, concebida por meio de um leilão hipotético, no qual os participantes dão lances para obter o conjunto de bens que desejarem. Entretanto, reconhecendo que todos estão sujeitos a eventos que podem representar situações de risco ou vulnerabilidade social, parte destes recursos deve ser alocada num sistema de seguro (DWORKIN, 2005).

Acontece que estas teorias por vezes ignoram que algumas privações, em especial de grupos culturais minoritários, classificados em minorias nacionais e minorias étnicas (KYMLICKA, 1995). Para Kymlicka (1995), numa concepção que pode ser chamada de liberalismo multicultural, para que os indivíduos possam ter autonomia, primeiro devem ter condições de escolher como 
viver sua vida, segundo suas próprias crenças, o que envolve alguma relação com a cultura da sociedade na qual estão inseridos, que fornece sentido à vida, por meio de atividades sociais, educacionais, religiosas e econômicas. No caso das minorias nacionais podem ser necessárias proteções externas como direito a autogoverno (autonomia política para administrar seu território), direitos poliétnicos (para preservar sua cultura) e direitos de representação (reservar vagas no Legislativo para seu grupo).

Em que pese a apertada síntese, o que se buscou evidenciar é que apesar de algumas semelhanças em suas concepções, como a defesa de um conjunto mínimo de direitos, existem claras divergências entre os autores. E mais do que isso, a visão de justiça ou de igualdade de cada um possui um sentido normativo.

A primeira consequência do sentido normativo de justiça/igualdade é que as instituições políticas, sociais e econômicas poderão ser analisadas sob este prisma e, se forem incompatíveis com a teoria, devem ser alteradas.

Em segundo lugar, a escolha de uma variável para medir a igualdade vai justificar a existência de determinados arranjos políticos até que esta igualdade seja alcançada. O melhor exemplo para compreender esta afirmação é a seleção pela igualdade de renda: até que todos tenham os mesmos rendimentos, programas de redistribuição de riqueza são necessários e condições fáticas podem demandar que tais políticas sejam permanentes.

A depender da teoria, a igualdade pode ser de direitos civis e políticos perante a lei (igualdade formal), ou uma igualdade de renda mais incisiva (uma versão de igualdade material próxima do pensamento do marxismo analítico). Uma forma de entender a igualdade material dentro da justiça liberal é a igualdade em dignidade humana, a abranger direitos fundamentais civis, políticos, sociais, culturais, econômicos e difusos, dentro de alguns limites que respeitem a responsabilidade individual.

A mesma teoria aplicada a contextos diferentes pode levar a resultados diferentes: se for uma sociedade, por exemplo, em que não existem direitos políticos ou sociais, com baixo IDH, a atuação do Estado pode ser mais incisiva. Ou ainda, se for uma sociedade que assegura alguns direitos civis e políticos, com PIB alto, mas com concentração de riqueza, podem ser necessárias outras medidas. Em resumo, está se buscando identificar o que pode ser distribuído e de que forma.

Outro exemplo de implementação destas teorias envolve a tributação progressiva sobre rendimentos, na qual pessoas que auferem maiores rendas sofrem a incidência de alíquotas 
maiores no pagamento de tributos. Ao mesmo tempo, o Estado é responsável por fornecer uma espécie de "seguro social", que pode ser educação e saúde pública, para proteger os indivíduos de situações de vulnerabilidade ou que não escolheram. Por outro lado, o Estado não deve arcar com todo e qualquer infortúnio, pois as pessoas devem ser responsáveis pelas suas escolhas.

Logo, a justiça/igualdade liberal não se resume à igualdade formal, ou à liberdade absoluta do liberalismo clássico, aproximando-se mais da noção de igualdade material, que reconhece que há casos em que as pessoas merecem o mesmo tratamento e há outros em que um tratamento diferenciado é imprescindível.

Portanto, é feita uma separação entre situações de privação involuntárias e voluntárias, para servir de guia para quando o Estado deve agir para satisfazer as necessidades básicas (SEN, 2008). Para selecionar quais as necessidades reconhecidas como materialmente fundamentais são de responsabilidade estatal basta examinar os direitos fundamentais previstos na Constituição Federal. A forma de implementação pode variar desde a prestação estatal direta, por exemplo, com a disponibilização de órgãos que cuidem da saúde, ou por meio da regulamentação, como pode ser o caso de leis que disciplinem a prestação de serviços de saúde pela iniciativa privada, ou um sistema misto, em que estas duas formas coexistam (prestação direta e regulamentação).

Ademais, pelo menos alguns aspectos do liberalismo igualitário são compatíveis com o texto constitucional (CITTADINO, 2009), que afirma que a dignidade é um dos fundamentos da República Federativa do Brasil (art. 1으, III, CF), que possui como seus objetivos fundamentais definidos constitucionalmente a diminuição das desigualdades sociais (art. 3ำ III, CF) e a promoção do bem de todos, sem distinção (art. 3o, IV, CF), e dispõe que todos são iguais perante a lei, sem distinção de qualquer natureza (art. 5ㅇ, CF).

\subsection{Capacidades e funcionamentos}

Acontece que para Sen (2008), que usa como principal referência para sua crítica a justiça como equidade de Rawls e, de certa forma a igualdade de recursos de Dworkin, a simples distribuição de bens ou de recursos não garante a igualdade, pois bens ou recursos, por si só, não permitem avaliar a extensão da liberdade fática.

A liberdade real é o meio e o fim do desenvolvimento, pois permite às pessoas viverem a vida de forma digna e englobam, no mínimo, liberdades políticas, facilidades econômicas, 
oportunidades sociais, garantias de transparência e segurança protetora, conferindo-lhes a capacidade de agente, a capacidade de escolher viver a vida que se deseja (SEN, 2000).

Nesse passo, Sen (2008) quer diferenciar a extensão da liberdade dos meios para a liberdade. Inicialmente, não é possível elaborar uma teoria normativa do ordenamento social, coerentemente, que rejeite a igualdade ou a igual consideração pelos integrantes da sociedade (SEN, 2008).

Este raciocínio leva à conclusão de que a questão não é saber se a igualdade deve ou não ser defendida, mas sim definir qual a igualdade que assegure a justiça. Desta forma, selecionar a igualdade num espaço, como a renda, pode levar à redistribuição de recursos numa sociedade até que todos tenham aproximadamente a mesma renda. O problema é que não se sabe o que as pessoas irão fazer com a renda, porque pessoas diferentes usam esses recursos distintamente.

As características físicas e sociais podem levar a grandes variações em bem-estar, na conversão da renda em outros bens. Uma mulher grávida pode ter necessidades distintas de uma pessoa com deficiência, ou ainda de uma pessoa jovem que não esteja em nenhuma destas situações. Nos dois primeiros casos a renda poderá ser usada com remédios ou com outros bens semelhantes (para cuidar da gravidez e da deficiência), enquanto no terceiro caso a pessoa com a mesma renda poderá usar seus recursos com outros bens, com maior potencial de obter bem-estar.

Esta afirmação não ignora que muitas pessoas com baixa renda também estão em condições de privação, e que aumentar sua renda pode lhe permitir adquirir bens essenciais. Todavia, existem fatores que podem caracterizar situações de privações, sem relação direta com a renda auferida por um indivíduo, como a falta de acesso à saúde ou a ausência de políticas para deficientes (SEN, 2008). A seleção de uma variável vai torná-la uma justificativa para a atuação estatal.

Os recursos dworkianos ou bens rawlsianos são meios para que uma pessoa atinja determinado fim: o dinheiro ou a renda não são importantes em si, eles são importantes porque possibilitam a aquisição de bens essenciais por indivíduos.

Segundo Sen $(2000$; 2008; 2011) funcionamentos são estados e ações, consistindo no que uma pessoa pode realizar ou não com sua vida. Nesse sentido, funcionamentos estão relacionados com o bem-estar individual e coletivo. Os funcionamentos relevantes podem ser estar nutrido ou em boa saúde, dentre outros.

O conjunto de funcionamentos que uma pessoa pode realizar é denominado de capacidade, refletindo a liberdade substantiva de escolher entre diferentes combinações de estados ou ações. Nesse passo, pode-se identificar o espaço de avaliação para medir a igualdade, 
como a capacidade e os funcionamentos. Para escolher quais os funcionamentos são relevantes é possível utilizar de processos de deliberação políticos tradicionais, de consulta à população ou de decisões jurisdicionais. Há formas de se reconhecer a diversidade humana em alguns aspectos, mas não em todos - gênero, etnia, idade e classe social podem ser relevantes em algumas circunstâncias, mas não em todas.

No Brasil, por exemplo, há legislação trabalhista, cotas em universidades públicas para pessoas de baixa renda, cotas em concursos públicos para pessoas que se declarem negras ou pardas e Estatuto do Idoso.

Isto não quer dizer que estas normas foram elaboradas com base na teoria de $A$. Sen, ou que alguns desses programas ou leis não necessitem de ajustes, mas o que se pretende demonstrar é que alguns de seus princípios são exequíveis ao considerar a diversidade humana na formulação de políticas públicas.

Ao se considerar a capacidade como um conjunto de funcionamentos, a sua abordagem permite a análise das mais variadas formas de pobreza e de como combatê-las. Sistemas públicos de saúde estão diretamente relacionados com a expectativa de vida da população e a existência de educação pública básica permite que mais pessoas sejam alfabetizadas e com acesso a níveis mais altos de educação, o que pode levar a maiores preocupações na área da saúde e, consequentemente, há aumento da qualidade de vida e melhores condições de ter participação política e de buscar emprego, o que pode aumentar renda (SEN, 2008, 2000).

Seria possível visualizar este como um sistema em que um grupo de direitos reforça os demais, permitindo que as pessoas vivam com dignidade. Dentre deste enfoque, Nussbaum (2001) contribuiu com a elaboração de um índice de capacidades humanas básicas, para guiar o desenvolvimento de políticas públicas, que de maneira simples, podem ser resumidas em: ser capaz de viver até o fim de uma vida humana completa; não morrer prematuramente; ser capaz de ter boa saúde, incluindo saúde reprodutiva; ser adequadamente nutrido; ter abrigo adequado; ser capaz de se mover livremente de um lugar para outro; estar seguro contra ataques violentos; ser capaz de usar os sentidos, imaginar, pensar e raciocinar; ser capaz de formar uma concepção de bem e planejar sua própria vida; ser capaz de se entreter com atividades recreativas; e ser capaz de viver a própria vida no seu próprio contexto.

Estas capacidades podem ser traduzidas na linguagem de direitos fundamentais e quando ausentes podem ser demandadas ao Estado. O fato de ser uma lista de capacidades é para dar 
espaço para a escolha individual de como exercê-las, ao invés de ser uma lista de funcionamentos básicos.

Por conseguinte, a ausência destas capacidades básicas, compreendidas como direitos fundamentais, ensejam que o titular do direito desrespeitado tenha direito de ação jurisdicional, pois o Estado é obrigado a assegurar algum bem-estar material (OUTEIRO; OLIVEIRA; NASCIMENTO, 2016). O que não quer dizer que o titular pode exigir judicialmente qualquer prestação fática com base nesse direito, pois é necessário examinar o conteúdo do direito à luz da teoria.

A abordagem da igualdade de capacidades e de funcionamentos ajuda a notar que a implementação de diferentes medidas aumenta a oportunidade de se viver com dignidade. Os direitos sociais reforçam os direitos civis e difusos e vice-versa. Assim, é possível avançar para o direito social à moradia e a sua relação com a Reurb.

\section{Direito à moradia e regularização fundiária urbana}

A importância do debater as configurações políticas é evidenciada quando se nota que muitos assuntos, como planejamento urbano e sustentabilidade, têm entrado na pauta de discussão da sociedade e as decisões afetam toda a coletividade.

Os direitos sociais estão intrinsicamente ligados à igualdade material, pois foram forjados baseados em reinvindicações relacionadas à promoção de bem-estar entre grupos, como de trabalhadores (ABRAMOVICH e COURTIS, 2006). Estes direitos incluem educação, saúde, moradia e alimentação, dentre outros, como dispõe o art. 6 da Carta Magna de 88.

A capacidade básica, que é relevante para a presente pesquisa, é o de habitar com dignidade - que pode ser desdobrados em funcionamentos mais específicos como o de ser dono de uma moradia digna. Além de ser um direito social reconhecido constitucionalmente como fundamental, existe um leque de dispositivos infraconstitucionais e internacionais que tratam do assunto.

Se existem pessoas que não conseguem usufruir desse direito, o Estado tem o dever de agir para que estas possam habitar em um local em que seja possível estabelecer relações sociais e atingir seu pleno desenvolvimento. 
O enfoque nas capacidades também serve para demonstrar que alguns programas públicos relacionados à habitação podem ser insuficientes, caso o objetivo seja assegurar uma moradia digna a todos. Em alguns casos, esses projetos visam facilitar o acesso ao crédito bancário para a população de baixa renda, como ocorre com algumas linhas de créditos disponíveis em bancos públicos para financiamento de moradia, que tem exemplo mais conhecido atualmente o Programa Minha Casa, Minha Vida, instituído pela Lei no 11.977/2009.

A título de ilustração, dentre outros grupos, existem dois tipos de pessoas que não são alcançadas: as que estão em situação de irregularidade e não possuem título que lhes assegure o acesso ao crédito; e as que estão dentro do grupo de renda tão baixa (ou que não tem nenhuma renda) que dificilmente conseguem pagar as mensalidades.

Isso não significa que essa política seja, per si, injusta ou errada, mas ela pode ser insuficiente, na hipótese de não estar acompanhada com outros programas que visem àquelas que estão excluídas.

No que tange ao ordenamento jurídico pátrio infraconstitucional, pode-se destacar as seguintes normas federais e instrumentos correlatos que disciplinam o direito à moradia ou definem formas de sua efetivação, em alguma de suas dimensões:

1 Estatuto da Cidade - Instrumentos Imposto Predial e Territorial Urbano (IPTU) progressivo Lei $\mathrm{n}$ - 10.257/2001 no tempo Parcelamento e edificação compulsórios Usucapião especial de imóvel urbano Zonas Especiais de Interesse Social Direito de preempção Concessão de direito real de uso (CDRU) Concessão de uso especial para fins de moradia (CUEM) Normas sobre Plano Diretor Municipal (PDM)

2 Lei do Sistema Nacional de Habitação - Lei no $11.124 / 2005$

3 Lei do Parcelamento do Solo Urbano - Lei no 6.766/1979

4 Programa Minha Casa Minha Vida - Lei no 11.977/2009

5 Lei que dispõe sobre regularização fundiária - Lei no $13.465 / 2009$
Criou o Fundo Nacional de Habitação de Interesse Social e tem como um de seus objetivos viabilizar para a população de menor renda o acesso à terra urbanizada e à habitação digna e sustentável

Flexibiliza alguns parâmetros urbanísticos quando se tratar de loteamento destinado à habitação de interesse social

Subsidia a aquisição de imóveis para famílias classificadas como de baixa renda na tipologia da legislação

Define procedimentos e regras sobre a Reurb, além de criar institutos jurídicos para implementar a Reurb 
No plano internacional cabe mencionar: o Pacto Internacional de Direitos Econômicos, Sociais e Culturais; a Declaração de Vancouver sobre assentamentos humanos; a Declaração de Istambul sobre assentamentos humanos; e a Declaração sobre as cidades e outros assentamentos humanos no Novo Milênio

Mas no que se refere ao conteúdo do direito à moradia, uma resolução elaborada pelo Comitê de Direitos Econômicos, Sociais e Culturais das Nações Unidas (CDESC), denominada Comentário Geral n. 4, aprovada na sessão de 13 de dezembro de 1992, foi feita para defini-lo, com base no Pacto Internacional de Direitos Econômicos, Sociais e Culturais de 1966.

Este comentário trata dos componentes do direito à moradia adequada, podendo identificá-los como seu conteúdo essencial, que são:

1. Segurança jurídica da posse;

2. Disponibilidade de serviços, materiais, equipamentos e infraestrutura;

3. Acessibilidade;

4. Habitabilidade;

5. Acessibilidade para grupos vulneráveis;

6. Localização;

7. Adequação cultural.

Segundo o Comentário Geral n. 4 do CESCR uma moradia digna não se resume à habitação ou abrigo, abarcando, especialmente, a proteção legal do imóvel e infraestrutura. Há fatores para analisar a moradia como o acesso aos serviços de saúde e a proteção jurídica da posse, que não precisa se confundir com a propriedade privada. Com efeito, o direito à moradia pode ser desvinculado da propriedade privada (MARTINS; MASTRODI, 2018).

Ademais, em casos em que já existem ocupações consolidadas em assentamentos informais, a retirada das pessoas de um local em que já estabeleceram suas relações sociais pode ser mais danosa à proteção do direito à moradia do que a realização de projetos de Reurb.

Naturalmente, deve-se considerar a Reurb como um processo pluridimensional, que não se resume a regularização jurídica, pois abarca também a regularização urbanística e o fornecimento de infraestrutura básica (FERNANDES, 2006).

A regularização jurídica pode ser um primeiro passo para, em seguida, proceder à dimensão urbanística da Reurb, com a execução de obras públicas capazes de promover melhores condições 
de vida para as famílias ocupantes de assentamentos irregulares. As medidas podem abarcar a instalação de equipamentos urbanos, como postos de saúde, a construção ou reforma de habitações, o fornecimento de energia elétrica e água tratada, dentre outras.

Por essa razão, os projetos de Reurb que, a título de ilustração, visam à garantia da segurança jurídica da posse e melhoria da qualidade de vida aos moradores de baixa renda, podem ser ainda mais relevantes socialmente, tendo em vista a redistribuição de bens sociais escassos para aqueles que são mais vulneráveis.

Reconhecendo a necessidade de sistematizar o tratamento legal à Reurb, a terceira parte da lei que disciplinou o Programa Minha Casa, Minha Vida, em 2009, trouxe um capítulo sobre a Reurb (posteriormente revogado pela Lei no 13.465/2017). No mesmo ano, ao constatar o nível de irregularidade urbana na Amazônia, foi instituído o PTL pelo Governo Federal, por meio da Lei no 11.952/2009.

Deste modo, deve-se analisar a estrutura desta lei à luz da igualdade de capacidades e da proteção do direito à moradia.

\section{A ESTRUTURA DO PROGRAMA TERRA LEGAL}

O PTL é aplicado na Amazônia Legal, em terras situadas em áreas da União - com a modificação promovida pela Lei no $13.465 / 2017$, este programa também pode ser aplicado a imóveis em outros locais, desde que observado o disposto no art. 40-A da Lei no 11.952/2009.

A Amazônia Legal foi criada com a finalidade de promover o desenvolvimento da região e hoje está prevista no art. 2을 da lei complementar no 124/2007, que abrange os Estados do Acre, Amapá, Amazonas, Mato Grosso, Rondônia, Roraima, Tocantins, Pará e do Maranhão na sua porção a oeste do Meridiano 44․

A Amazônia Legal possui área territorial de aproximadamente $5.020 .000 \mathrm{~km}^{2}$, correspondendo a cerca de $60 \%$ do território nacional e abrangendo 776 municípios, cuja população é de 27.971.552 habitantes (IBGE, 2017). Dentre os 502 milhões de hectares da Amazônia legal, 113 milhões (ou cerca de 22\% de sua área total) eram terras federais, sendo 58 milhões com alguma destinação e o restante, 55 milhões, estava sem destinação até o início do PTL (RIBEIRO; SILVA; SANTOS, 2016). 
A premissa do PTL é tratar da regularização fundiária rural e urbana, em que cada uma destas espécies conta com condicionantes e contornos próprios, mas trazendo, em ambas modalidades, a preferência para a titulação das comunidades locais.

Na regularização fundiária rural, os ocupantes devem atender às exigências legais, dentre as quais cabe destacar a ocupação e a exploração direta de atividade econômica exercida em imóvel rural, mansa e pacificamente, por si ou por seus antecessores.

Na Reurb há o intuito de transferir o domínio pleno das terras federais ocupadas pela população aos municípios, com vistas a beneficiar a comunidade local. Acontece que o PTL exige contrapartidas dos municípios para que possam ser beneficiados com a alienação das áreas, sendo obrigatório que as administrações locais promovam os atos necessários à regularização das áreas ocupadas (art. 21, $\$ 1$, Lei no 11.952/2009) e que haja lei municipal, que pode ser tanto o Plano Diretor Municipal, quanto outra lei específica, que abranja a área a ser regularizada (art. 22, § 1으, Lei no 11.952/2009).

Entretanto, quando se tratar de áreas com ocupações para fins urbanos já consolidadas a transferência da área poderá ser feita independentemente da existência da lei municipal (art. 22, §2으, Lei no 11.952/2009). De acordo com o art. 2º, l, "a" e "b", do Decreto no 7.341/2010, que regulamenta o PTL, consideram-se áreas com ocupações para fins urbanos já consolidadas aquelas que apresentam sistema viário implantado com vias de circulação pavimentadas ou não, que configuram a área urbana por meio de quadras e lotes; uso predominantemente urbano, caracterizado pela existência de instalações e edificações residenciais, comerciais, voltadas à prestação de serviços, industriais, institucionais ou mistas, bem como demais equipamentos públicos urbanos e comunitários.

O art. 1ำ, parágrafo único da Lei no 11.952/2009 proíbe beneficiar pessoa natural ou jurídica com a regularização de mais de uma área ocupada. No entanto, com a Lei № 13.465/2017 ocorreram modificações em relação aos critérios que serviriam de guia para a atuação dos municípios. Anteriormente, as condicionantes presentes na Lei Federal 11.952/2009, estavam em seu art. 30. Em linhas gerais, existiam 4 situações:

1) alienação gratuita para ocupantes de baixa renda, em imóveis de até $1.000 \mathrm{~m}^{2}$, que tenham ingressado na área antes de fevereiro de 2009 e usem o imóvel como única moradia ou meio lícito de sobrevivência;

2) alienação onerosa, precedida de licitação, para imóveis entre $1.000 \mathrm{~m}^{2}$ e $5.000 \mathrm{~m}^{2}$;

3) alienação gratuita para órgãos e entidades da administração pública estadual e; 
4) nos demais casos, aplica-se a Lei de Licitações e Contratos (Lei 8.666/1993), em que é possível haver venda direta ou licitação.

Para ter direito à alienação gratuita do imóvel, o morador devia auferir renda familiar mensal inferior a 5 salários mínimos e ocupar área de até $1.000 \mathrm{~m}^{2}$, sem oposição, pelo prazo ininterrupto de, no mínimo, 1 ano, desde 2009, utilizando o imóvel como única moradia ou como meio lícito de subsistência, exceto locação ou assemelhado. Por fim, não podia ser proprietário ou possuidor de outro imóvel urbano.

Os casos de licitação eram para imóveis acima de $1.000 \mathrm{~m}^{2}$, enquanto a alienação gratuita para órgãos e entidade estaduais estava ligada aos casos de haver prédios públicos nas glebas doadas. O último caso, aplicado de forma subsidiária, quando o imóvel não se enquadrasse nas hipóteses anteriores, é o da Lei de Licitações, que permite a venda direta, sem licitação, ou a alienação precedida de procedimento licitatório.

No formato anterior havia uma série de requisitos que poderiam ser justificado à luz da igualdade de capacidades: para pessoa natural de baixa renda, definida conforme a Lei № 11.952/2009, seria possível receber por meio de doação o imóvel destinado à habitação, desde que não fosse possuidor ou proprietário de outro imóvel. Com base no referencial teórico, a quantidade de requisitos permite falar em direito subjetivo do ocupante à Reurb, com possibilidade de exigir judicialmente seu direito (OUTEIRO; NASCIMENTO, 2016).

Não seria inconsistente com a igualdade de capacidades exigir que pessoas que possuíssem mais de 1 imóvel ou com renda superior a 5 salários mínimos tivessem que pagar pelo bem, que era em sua origem público. Apesar do principal fator aqui ser renda, e como foi dito nas seções anteriores, a renda não permite perceber variações naturais e sociais que coloquem os indivíduos em situação de privação, a ideia não é impedir a Reurb. Mas sim, distinguir entre pessoas que podem estar em situação de maior pobreza do que outras.

Um ajuste na legislação que pudesse levar em consideração a idade avançada ou outra situação para beneficiar os moradores, ampliando o limite de renda também seria possível. Mas haver um limite, como beneficiar o ocupante apenas 1 vez ou traçar uma linha divisória é importante para evitar os chamados free riders, que poderiam se beneficiar de um programa de Reurb, alienar o imóvel em seguida, para depois tentar serem contemplados de novo. Outra forma de evitar este problema é melhorar os mecanismos de fiscalização e monitoramento das ações da Reurb com base no PTL. 
O limite de tempo (de ocupar por no mínimo 1 ano desde 2009) também funcionava na mesma linha de raciocínio, para não estimular novas ocupações irregulares, que poderiam ocorrer após a lei entrar em vigor.

Atualmente, o art. 30 afirma que o Município deverá efetuar a regularização fundiária das áreas doadas pela União mediante a aplicação dos instrumentos previstos na legislação federal específica da Reurb, que é a Lei no 13.465/2017.

Esta nova lei teve a finalidade de desburocratizar os procedimentos da Reurb e trouxe novidades em relação aos institutos e mecanismos de regularização, além de alterar algumas regras do PTL. Dentre outras inovações, a Reurb agora também alcança imóveis em núcleos informais com características urbanas, mesmo que situados em zonas rurais; além de ter sido criado o direito real de laje; e a legitimação de posse ganhou contornos que a assemelham a um usucapião administrativo, sem necessidade de recorrer ao Judiciário.

Ao mesmo tempo, mantém outros institutos ou conceitos, como a distinção entre Reurb de interesse social, sendo aquela regularização fundiária aplicável aos núcleos urbanos informais ocupados predominantemente por população de baixa renda, declarados em ato do Executivo municipal; e Reurb de interesse específico, definida como aquela em que a população não está qualificada como de baixa renda. A diferença é importante porque, dentre outros fatores, há a flexibilização de parâmetros urbanísticos e uma série de isenções de custas e de emolumentos para a Reurb de interesse social.

Para Tartuce (2018, p. 3-4), as principais modificações introduzidas no Direito pátrio a partir desta lei foram: a) introdução do direito real de laje no rol do art. 1.225 do Código Civil; b) regulamentação do direito real de laje no Código Civil e na Lei de Registros Públicos (Lei no 6.015/1973); c) alteração dos requisitos para a usucapião urbana coletiva, tratada pelo Estatuto da Cidade; d) modificações no tratamento da usucapião extrajudicial ou administrativa, sanando algumas dúvidas (alterações no art. 216-A da Lei de Registros Públicos, incluído pelo CPC/2015); e) introdução de novas modalidades de condomínio: o condomínio de lotes e o condomínio urbano simples; f) regulamentação do sistema de arrecadação de bens vagos, para os casos de abandono (o art. 1.276 do Código Civil); g) revogação de todo o capítulo da Lei Minha Casa, Minha Vida (Lei 11.977/2009) relativo à regularização fundiária; h) alterações de procedimentos relativos à alienação fiduciária em garantia de bens imóveis, facilitando o recebimento dos créditos; i) modificações na Medida Provisória no 2.220, que trata da concessão especial de uso; j) alterações da Lei no 9.636/1998, que trata da alienação de bens imóveis da União, facilitando a extinção da 
enfiteuse sobre terras da Marinha; k) introdução de políticas para Regularização Fundiária Urbana; e l) introdução do instituto da legitimação fundiária

Todavia, a maior novidade da Lei no $13.465 / 2017$, quanto ao PTL, foi a determinação da utilização dos seus instrumentos de regularização, dentre os quais está este instituto acima mencionado de legitimação fundiária. Prevista nos artigos 23 e 24 desta lei, a legitimação fundiária constitui forma originária de aquisição do direito de propriedade, àquele que detiver em área pública ou possuir em área privada, como sua, unidade imobiliária com destinação urbana, integrante de núcleo urbano informal consolidado existente em 22 de dezembro de 2016.

O ocupante que adquirir a propriedade, mediante legitimação fundiária, recebe a unidade imobiliária livre e desembaraçada de quaisquer ônus, direitos reais, gravames ou inscrições, eventualmente existentes em sua matrícula de origem, e, por ser aquisição originária de propriedade, não incide pagamentos de tributos, como impostos de transferência de bens imóveis - Imposto sobre a Transmissão de Bens Imóveis e de direitos a eles relativos (ITBI) e Imposto sobre Transmissão "Causa Mortis" e Doação (ITCMD).

A possibilidade de adquirir uma propriedade pública sem ônus e sem nenhum outro requisito, exceto na modalidade de Reurb de interesse social, que não seja a ocupação do imóvel antes de 22 de dezembro de 2016, mais se assemelha a novas formas de grilagem e pode facilitar a acumulação de terras em favor de pessoas de alta renda, ao invés de democratizar o acesso ao solo urbano em favor de pessoas de baixa renda. O principal requisito na nova lei, aplicado somente na Reurb de interesse social, é que o ocupante não pode ser proprietário, concessionário ou foreiro de outro imóvel (art. 23, §1으, Lei no 13.465/2017). Na outra espécie de Reurb não há nenhum requisito além da ocupação do imóvel antes de 22 de dezembro de 2016.

Não é levado em consideração o tempo de ocupação e o tamanho do imóvel. Um imóvel com dimensões superiores a $1.000 \mathrm{~m}^{2}$ pode ter sido ocupado em novembro de 2016 e terá o mesmo tratamento que áreas ocupadas há décadas com lotes com menos de $100 \mathrm{~m}^{2}$.

Isto evidencia que a tentativa de facilitar a Reurb modificou a política de regularização iniciada com o PTL, em 2009, não sendo adequada à luz da igualdade de capacidades, pelo potencial de beneficiar grileiros (SAUER; LEITE, 2017).

Para facilitar a compreensão, como se pode observar no Quadro 1.

Quadro 1 - Critérios de regularização fundiária urbana do Programa Terra Legal. 


\begin{tabular}{|c|c|}
\hline \multicolumn{2}{|c|}{ Critérios de regularização fundiária do Programa Terra Legal } \\
\hline Até a Lei no 13.465/2017 (entre 2009-2017) & Após a Lei no 13.465/2017 \\
\hline $\begin{array}{l}\text { Dever dos municípios de atuarem para efetuar } \\
\text { a regularização fundiária na área doada }\end{array}$ & $\begin{array}{l}\text { Dever dos municípios de atuarem para efetuar } \\
\text { a regularização fundiária na área doada }\end{array}$ \\
\hline $\begin{array}{l}\text { Art. 30, Lei no } 11.952 / 2009 \text { - Critérios: } \\
\text { I - alienação gratuita a pessoa natural que tenha } \\
\text { ingressado na área antes de } 11 \text { de fevereiro de } \\
2009 \text {, desde que: } \\
\text { a) possua renda familiar mensal inferior a } 5 \\
\text { salários mínimos; } \\
\text { b) ocupe a área de até } 1.000 m^{2} \text {, pelo prazo } \\
\text { ininterrupto de, no mínimo, } 1 \text { ano; } \\
\text { c) utilize o imóvel como única moradia ou } \\
\text { como meio lícito de subsistência; e } \\
\text { d) não seja proprietário ou possuidor de } \\
\text { outro imóvel urbano; } \\
\text { II-alienação gratuita para órgãos e entidades da } \\
\text { administração pública estadual, instalados até } \\
11 \text { de fevereiro de } 2009 \text {; } \\
\text { III - alienação onerosa, precedida de licitação, } \\
\text { com direito de preferência àquele que } \\
\text { comprove a ocupação, por } 1 \text { (um) ano } \\
\text { ininterrupto, sem oposição, até } 10 \text { de fevereiro } \\
\text { de } 2009 \text {, de área superior a } 1.000 m^{2} \text { e inferior a } \\
5.000 m^{2} \text {; e } \\
\text { IV - nos demais casos, possibilidade de aplicar a } \\
\text { venda direta, observada a alínea } f \text { do inciso I do } \\
\text { art. } 17 \text { e as demais disposições da Lei no } \\
8.666 / 1993\end{array}$ & $\begin{array}{l}\text { Art. 30, Lei no } 11.952 / 2009 \text { - Sem critérios } \\
\text { Critério da Lei no } 13.465 / 2017-\text { Possibilidade de } \\
\text { aplicar a legitimação fundiária, àquele que } \\
\text { detiver em área pública ou possuir em área } \\
\text { privada, como sua, unidade imobiliária, } \\
\text { integrante de núcleo urbano informal } \\
\text { consolidado existente em } 22 \text { de dezembro de } \\
2016 \text {, ou outros instrumentos previstos na Lei. }\end{array}$ \\
\hline
\end{tabular}

Fonte: Elaborado com base no PTL e Lei no 13.465/2017.

Ao se executar a Reurb segundo as novas regras, é possível projetar que qualquer ocupante conseguirá obter a proteção da posse, independentemente da origem de sua relação com o terreno: grileiros, ocupantes legítimos e políticos. Não há separação entre pessoas que destituídas da capacidade de habitar com dignidade das demais.

Até dezembro de 2018 foram ajuizadas três Ações Direta de Inconstitucionalidade (ADIs 5771, 5787 e 5883) contra dispositivos da Lei no 13.465/2017 no Supremo Tribunal Federal, distribuídas ao ministro Luiz Fux. Em linhas gerais, além do argumento de interferência da União nas competências municipais de realizar o ordenamento territorial, outro problema identificado é que esta lei viola outros dispositivos constitucionais, incluindo alguns que versam sobre direitos fundamentais, pondo-se em contraposição aos princípios delineados de planejamento urbano e política urbana previstos na Lei Maior. 
Por conseguinte, cabe destacar que a atual estrutura jurídica do PTL combinado com a Lei no 13.465/2017 se inclina a legalizar a desigualdade, sendo, nesses termos, injusta e em desacordo com o ideal da igualdade de capacidades.

A justiça liberal exigiria, ainda que haja algum espaço para definir aspectos mais concretos que podem se utilizar de subsídios de profissionais de outras áreas do conhecimento, como historiadores, geógrafos, urbanistas, dentre outros, que:

1) A Lei no $13.465 / 2017$ seja declarada inconstitucional;

2) O PTL seja ser alterado para utilizar critérios de inclusão social ao beneficiar com alienação gratuita para ocupantes de terras públicas e, enquanto não for modificado ou declarado inconstitucional, que os municípios adotem critérios semelhantes;

3) Instituição de mecanismos de fiscalização e monitoramento para evitar fraudes.

A justiça é a primeira virtude das instituições políticas (RAWLS, 2008) e em caso de inadequação cabe aos juristas discutirem formas de aperfeiçoamento dos arranjos institucionais em prol da igualdade entre todos. O que se espera, mais do que respostas prontas e perfeitas, é que as perguntas gerem inquietações para que mentes mais doutas e advogados públicos e privados, juízes e promotores atuem com vistas à concretização dos objetivos constitucionais de construir uma sociedade mais justa e igualitária.

\section{CONCLUSÃO}

A abordagem de capacidades permitiu examinar a estrutura normativa do PTL na Amazônia, de maneira que se constatou que no desenho institucional atual permite a grilagem de terras públicas e acumulação de terras.

Com efeito, a legislação permite que a Reurb seja executada sem critérios rígidos que busquem uma reforma urbana igualitária, com vistas à construção de cidades inclusivas, que possam ser usufruídas por todos.

A igualdade liberal não dá todas as respostas, mas aponta caminhos, dentro de suas próprias limitações, para a discussão de leis e institutos, a partir de um sentido normativo de justiça. Mesmo que a teoria seja feita com base em um modelo ideal e, nesse sentido, mais abstrato, cabe aos juristas buscarem formas de efetivar a justiça, ainda que não se alcance num primeiro momento 
o modelo ideal. Por isso, considerando a realidade e as limitações fáticas, o que a justiça requer no presente não deve ser deixado de lado, pois assim, a igualdade não será apenas algo teórico, mas sim concreto.

\section{REFERÊNCIAS}

ABRAMOVICH, V.; COURTIS, C. El umbral de la ciudadanía: el significado de los derechos sociales em el Estado social constitucional. Buenos Aires: Del Puerto, 2006.

ARISTÓTELES. Ética a Nicômaco. 3. ed. Tradução de Mário da Gama Kury. Brasília: Editora Universidade de Brasília, 2001.

BRITO, B.; BARRETO, P. Primeiro ano do Programa Terra Legal: avaliação e recomendações. Belém: Imazon, 2010.

CITTADINO, G. Pluralismo, direito e justiça distributiva: elementos de filosofia constitucional contemporânea. 4. ed. Rio de Janeiro: Lumen Juris, 2009.

DWORKIN, R. A virtude soberana: teoria e a prática da igualdade. Trad. de Jussara Simões. São Paulo: Martins fontes, 2005.

GARGARELLA, R. As teorias da justiça depois de Rawls: um breve manual de filosofia política. São Paulo: Martins Fontes, 2008.

FERNANDES, E. Anova ordem jurídico-urbanística no Brasil. In: ALFONSIN, B. e FERNANDES, E. (Orgs.). Direito Urbanístico: estudos brasileiros e internacionais. Belo Horizonte: Del Rey, 2006, p. 3-23.

FLEISCHCKER, S. Uma breve história da justiça distributiva. Trad. de Álvaro de Vita. São Paulo: Martins Fontes, 2006.

IBGE. Pesquisa Nacional por Amostra de Domicílios (PNAD) 2015. 2015. Disponível em<http://www.ibge.gov.br/home/estatistica/pesquisas/pesquisa_resultados.php?id_pesquisa=4 0>. Acesso em: 10 jul. 2018. maio 2018.

Brasil em síntese. 2017. Disponível em <https://cidades.ibge.gov.br/brasil>. Acesso em: 10 
KYMLICKA, W. Filosofia política contemporânea: uma introdução. Trad. Luís Carlos Borges. São Paulo: Martins Fontes, 2006.

. Multicultural citizenship. Oxford: Clarendon Press, 1995.

MARTINS, E. G.; MASTRODI, J. Direito à Moradia: entre a efetivação autônoma e a sujeição ao direito de propriedade. Revista Direitos Fundamentais \& Democracia, v. 23, n. 2, p. 75-103, 2018.

NUSSBAUM, M. Womam and Human Development. Cambridge: Cambridge University Press, 2001.

OUTEIRO, G. M.; OLIVEIRA, M . C. C.; NASCIMENTO, D. M. A justiça como equidade de Rawls e a igualdade de Amartya Sen: uma releitura na construção de um sistema de proteção de direitos fundamentais. Revista do Direito Público, v. 11, n. 2, p. 47-81, 2016.

OUTEIRO, G. M.; NASCIMENTO, D. M. Direito humano à moradia e a regularização fundiária na Amazônia: limites e possibilidades. Pensar-Revista de Ciências Jurídicas, v. 21, n. 2, p. 507-533, 2016.

RAWLS, J. Uma teoria da justiça. 3. ed. São Paulo: Martins Fontes, 2008.

RIBEIRO, A. A.; SILVA, R. C.; SANTOS, J. L. Política de regularização fundiária em Rondônia: limitações do programa terra legal e expectativas socioterritoriais. Confins, Paris, v. 29, p. 1, 2016.

ROLNIK, R. A construção de uma política fundiária e de planejamento urbano para o país: avanços e desafios. Políticas Sociais: acompanhamento e análise, Brasília, IPEA, n. 12, p. 199-210, fev. 2006.

SAUER, S.; LEITE, A. Medida Provisória 759: descaminhos da reforma agrária e legalização da grilagem de terras no Brasil. Retratos de Assentamentos, v. 20, n. 1, p. 14-40, 2017.

SEN, A. La ideia de justicia. Buenos Aires: Aguilar, Altea, Tarus, Alfaguara, 2011.

Desigualdade reexaminada. 2. ed. Rio de Janeiro: Record, 2008.

. Desenvolvimento como liberdade. Trad. de Laura Teixeira Motta. São Paulo: Companhia das Letras, 2000. 
TARTUCE, F. A Lei da Regularização Fundiária (Lei 13.465/2017): análise inicial de suas principais repercussões para o direito de propriedade. Pensar-Revista de Ciências Jurídicas, v. 23, n. 3, p. 123, 2018.

VITA, Á. O liberalismo igualitário: sociedade democrática e justiça internacional. São Paulo: Martins Fontes, 2008.

Trabalho enviado em 23 de janeiro de 2019

Aceito em 20 de abril de 2020 